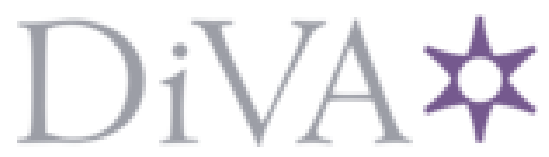

http://www.diva-portal.org

This is the published version of a paper published in International Journal of Physical Medicine Rehabilitation.

Citation for the original published paper (version of record):

Bråndal, A., Wester, P. (2013)

Stroke unit at home: A prospective observational implementation study for early supported discharge from the hospital.

International Journal of Physical Medicine Rehabilitation, 1(170)

http://dx.doi.org/10.4172/2329-9096.1000170

Access to the published version may require subscription.

N.B. When citing this work, cite the original published paper.

Permanent link to this version:

http://urn.kb.se/resolve?urn=urn:nbn:se:umu:diva-120077 


\title{
Stroke Unit at Home: A Prospective Observational Implementation Study for Early Supported Discharge from the Hospital
}

\section{Anna Brandal and Per Wester}

Umea Stroke Center, Department of Public Health and Clinical medicine, Umea University, S-901 87 Umea, Sweden

\begin{abstract}
Background: Randomized controlled trials on early supported discharge (ESD) service in stroke have demonstrated favorable results. However, there are difficulties in transferring research results regarding ESD to the clinic. The aim of this study is to describe the method, content, implementation and outcome of ESD in its natural habit for stroke patients.

Methods: A prospective observational implementation study of 153 consecutive stroke patients with mild to moderate severity with ESD and rehabilitation by a specially trained interdisciplinary team in the patient's home, directly after discharge from the stroke unit. The interdisciplinary team in the ESD team is similar to the work at the stroke unit. Number of patients/year, clinical and functional health status, patient satisfaction, accidental falls/other injuries and resources were evaluated.

Results: The number of patients/year in the ESD service has gradually increased from 2005 to 2009. The stroke patients subjected to Umea ESD service in January 2008 until May 2009 had a mean of 8.6 days of in-hospital care. The ESD service included 11 visits and $18 \mathrm{~h}$ per patient during 23 days (mean values). Compared with time of enrollment, patients exhibited reduced functional dependency (ADL- stairs $3(1-5)$ vs. $1(0-3)$, median, $Q_{1}-Q_{3}, p$ $<0.001$, two-sided Wilcoxon Signed Ranks test) and increased mobility (Rivermead Mobility Index, (RMI) 11 (9-13) vs. $13(12-15), p<0.001)$ at the time of discharge from the ESD service. Patient satisfaction regarding ESD was high. The
\end{abstract} long-term risk of accidental falls and other injuries appeared not to be increased.

Conclusions: It is possible to locally develop and implement ESD care for stroke patients based on evidencebased principles. Our locally adapted ESD care, a stroke unit in the patients' home, appears to be an appropriate alternative to conventional rehabilitation for patients with mild to moderate stroke.

Keywords: Stroke; Early supported discharge; Home rehabilitation; Implementation

\section{Introduction}

Stroke is a major health problem and a leading cause of death and disability worldwide [1]. Stroke consumes approximately $5 \%$ of health services resources, and much of the cost is attributable to the in-hospital care of disabled patients [2].

It has been well established that the stroke patient's needs are best met in an organized stroke unit [3].Stroke unit care is effective in reducing death and disability, as well as improvingpost-stroke outcomes [3]. Furthermore, an alternative service has been reported where stroke patients in hospitals are offered early supported discharge (ESD) with rehabilitation at home $[4,5]$. The ESD is conducted by multidisciplinary team members with experience in stroke rehabilitation and the ESD service could either have a community or a hospital base [4]. When appropriately resourced and provided for a selected group of stroke patients with mild to moderate severity,ESD can reduce the length of hospital stay[4,5]. In addition, a benefit to functional outcome has been reportedto reduce long-term dependency and admission to institutional care, with no apparent adverse impact on the mood or subjective health status of patients or carers [4-7]. However, the content of ESD for stroke patients is highly variable among different stroke organizations [4]. The ESD service thus needs to be locally adapted in order to enable appropriate implementation [8].

For the stroke patient, coming home from hospital is often an important step in understanding the disease and its consequences, as well as an opportunity for the individual to reclaim their own responsibility, find their own solutions and be more active in their rehabilitation. After discharge, patients have requested support, encouragement, advice, information about medications, and confirmation that recovery is progressing as expected and that their exercise is suitable [9].
In Sweden, approximately 88 percent of the stroke patients are admitted to and cared for at a stroke unit [10]. Umeå Stroke Center at the University Hospital of Umeå is a stroke unit responsible for acute care, nursing and sub-acute rehabilitation. All patients with acute onset of suspected cerebrovascular disease in the catchment area of Umeå and its surrounding municipalities (145000 inhabitants) are referred to Umeå Stroke Center.

In September 2004, the board of Västerbottens County Council in Northern Sweden gave stroke team members the commission to develop and implement an ESD service for stroke patients at the University Hospital of Umeå. The content of the locally adapted ESD was based on the published data about ESD after stroke care at hospital $[4,5]$ and our understanding from interviews with stroke patients after discharge [9].

The implementation process was done with support from members at the Memeolog department at Västerbottens County [11] who work with improvements in the health care [12]. For the implementation process, a specifically developed handbook for improvement with a practical approach to enhancing organizational performances with

${ }^{*}$ Corresponding author: Per Wester, Professor, Umea Stroke Center, Department of Public Health and Clinical medicine, Uma University, S-901 87 Umea, Sweden, Tel: +46 9078525 84; E-mail: per.wester@medicin.umu.se

Received October 19, 2013; Accepted November 25, 2013; Published November 29, 2013

Citation: Brandal A, Wester P (2013) Stroke Unit at Home: A Prospective Observational Implementation Study for Early Supported Discharge from the Hospital. Int J Phys Med Rehabil 1: 170. doi:10.4172/2329-9096.1000170

Copyright: $\odot 2013$ Brandal A, et al. This is an open-access article distributed under the terms of the Creative Commons Attribution License, which permits unrestricted use, distribution, and reproduction in any medium, provided the original author and source are credited. 
guidance [13] was used. A value compass [14,15] was used to describe and follow the progress of the implementation process at a group level.

The general aim of the present study is to describe the method, content, implementation and outcome of ESDin its natural habit for stroke patients.

Our hypothesishastree parts:(I) ESD according to the Umeå Stroke Center model is feasible in an selected stroke population; (II) Umeå Stroke Center ESD is associated with favorable clinical outcome; and (III) Umeå Stroke Center ESD is not associated with increased risk of accidental falls and other injuries.

\section{Methods}

\section{Participants}

The study participants were consecutively admitted to the stroke unit at the University Hospital of Umeå, Sweden, and were offered early discharge and rehabilitation at home by the ESD team. Patients were recruited according to the following inclusion criteria: preliminary or final diagnosis of acute stroke, medical stability, continued need for rehabilitation, independent living in Umeå or in the nearby surrounding areas and verbal consent from the patient and their family. Patients with severe stroke, i.e., with modified Rankin Scale>3 [16], serious co-morbidity with e.g. terminal cancer, hemodialysis, severe cognitive dysfunction, drug abuse and patients living far away from the hospital or in residential care facilities were excluded. Prior to hospital discharge the physician in charge for the patient at the stroke unit made the final decision if the patient was suitable for ESD. The team at the stroke unit made a survey of each participant's home situation, home environment and need of municipal assistance. If necessary, a home visit was conducted before discharge.

\section{ESD team and intervention}

The ESD-team members are a part of the stroke unit. The ESD team consists of one full-time working physiotherapist, one full-time working occupational therapist, and a part time $(50 \%)$ working nurse, part time (25\%) stroke physician and a part time (50\%) social worker. A speech therapist, psychologist and dietician are consulted when necessary. The ESD team works according to an interdisciplinary approach with daily coordination and team meeting once a week for medical discussions and planning. To achieve the efficient use of resources, the nurse specifically visits those who do not have an established contact with primary care contact. The stroke patients who have had a continuous contact with a nurse at primary care before stroke onset continues with such contact when coming home. These patients receive additional support/ rehabilitation from the occupational therapist, physiotherapist, social worker and physician in the ESD team. The ESD-teams assignment is to offer at-home rehabilitation for individuals with mild to moderate stroke.

Patients are informed and provide verbal consent to ESD directly after discharge from the stroke unit. ESD service is initially provided 5 days per week, which is successively reduced when the patient is more independent. The amount of rehabilitation, duration and intensity of intervention is determined by each patient's needs and goals in agreement with the patient and their family. The rehabilitation is recorded as treatment hours with each of the team's professions. Intervention consists of task-specific training in the patient's home and neighborhood. The choice of training activities is based on each patient's interests and goals. Patients and relatives are also continually informed about the disease, prognosis and risk factors and are provide with support and practical advice about how to manage everyday tasks, such as the adaptation and prioritization of activities, physical activity, rest and medication management. Rehabilitation progressis assessed continuously using standardized instruments for assessment of balance, mobility, arm-hand function and ADL, where the results are compared with the individuals' goals. At the time of dispatch from the ESD service, current information is transmitted in writing (and verbally if needed) to the next step in the chain of care, which usually includes primary health care and sometimes day rehabilitation facilities.

\section{Outcome measures}

The outcome of ESD is evaluated using a value compass $[14,15]$. The value compass (Figure 1) is a method for describing the value of care for a specific patient group in four dimensions - clinical status (number of patients per year; minimum, mean, median, maximum length of stay; and re-admissions), functional health status (ADL stairs and RMI), satisfaction in relation to needs (patient satisfaction according to an early version of the National Patient Survey for patients in Västerbotten County Council), and costs. Patients are re-admitted to the in-hospital stroke unit if the ESD services cannot guarantee safe health care and rehabilitation at home.

The Activity in Daily Life (ADL)-stairs [17] is a further development of the Katz ADL index [18]. Katz ADL index measures each individual's level of dependence in sex activities (eating, continence, transfer, toileting, bathing and dressing). In the ADL-stairs, four activities been added (cooking, transportation with public transportation, grocery shopping and cleaning). Step10 means that the individual is dependent on another person for all activities: at step 0 , the person is completely independent. The ADL-stairs has been tested for reliability and validity [17].

The River mead mobility index (RMI) [19-21] is a measure of disability related to bodily mobility; it includes 15 mobility items, which are hierarchically arranged and ordered according to ascending level of difficulty. The RMI covers a range of activities, from turning over in the bed to running. The range of scores is between 0 (poor mobility) and 15 (good mobility).The ADL-stairs and the RMI were measured at enrollment and discharge from the ESD service.

The ADL-stairs and the RMI were chosen to measure different aspect of functional health status, which could be summarized and used at a group level. Both measurements are easy and quick to perform.

\section{Functional}

Clinical

status

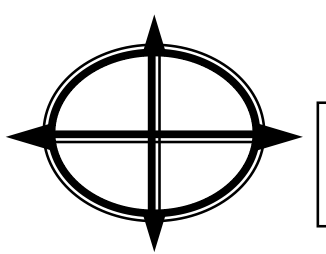

Satisfaction in relation to needs

\section{Costs and}

resourses

Figure 1: The value compass $[14,15]$ 
Patient satisfaction is measured using an early version of the National Patient Survey developed for patients in Västerbotten County Council [22]. The questionnaire consists of four questions regarding response, information, participation in care and treatment, and availability of care and treatment. Patient satisfaction is measured at discharge from the ESD services.

An economist calculates the cost of ESD on one occasion each year. The total cost includes staff, administrative costs, laboratory, general service, equipment, medical technology, internet, telephone and corporate costs. The costs of health and social care in the community have not been calculated.

The Abbreviated Injury Scale(AIS) [23] is used to grade accidental falls and other injuries. It is based on injury severity and location, and each individual injury is classified. The Maximal Abbreviated Injury Scale (MAIS) is a six-point scale that represent the maximum extent of damage $(1=$ mild injury, 6 = maximum, fatal injury).

The study is approved by the Regional Ethics Committee at UmeåUniversity.

\section{Data analyses}

All data for ESD were collected in an Excel file (Microsoft Office Exel 2003, Microsoft, USA).The Excel files for ESD, The Swedish Stroke Register and The Umeå University Hospitals injury registration were cross-classified to identify baseline characteristics, injuries and falls up to one year after stroke onset. Significance of differences between $\mathrm{ADL}$ and RMI at enrollment and at discharge was determined with the two-sided Wilcoxon signed rank test with a p-value $<0.05$. We used IBM SPSS for Windows, version 18.0, SPSS Inc., Chicago, IL for all calculations.

\section{Results}

We have in this study chosen to describe our testing and implementation work of the Umeå ESD service from 2004 to 2009 with presentation of results from January 2008 until May 2009, i.e., when the Umeå ESD service had been well established.

\section{Implementation of ESD for stroke patients Umeå}

The development and implementation of the ESD-service for stroke patients in Umeå started September 2004. The ESD-team was locally recruited from team members working at the stroke unit. Two members of the ESD team were responsible for the development and implementation process of the ESD and thus had a leader/coordinator function. This included working methods and procedures, structure of team meetings, information to patients, information meetings with officials in the municipality. However, the coordination of the practical work could be done by anyone in the ESD team and was depending on the patients needs. Table 1 shows that the number of patients/year has gradually increased from 2005 to 2009 .

When initiating the Umeå ESD stroke service in 2004, the focus was to pick up and gather experience that could increase confidence among the stroke unit team and ESD team members. For example the ESD service was tested in patients with different severity of stroke symptoms (mild to moderate and in a few cases more severe symptoms), in direct connection to the hospital discharge as well as after some time at in-hospital rehabilitation units. It was found that stroke patients with initially more severe symptoms could after a more prolonged rehabilitation phase at the stroke unit and thereby gradual recovery also be eligible for the ESD service. Furthermore different amounts of ESD resources were tested and calibrated based on individual needs.
Based on the experience with testing, initial implementation, retesting and further implementation, a locally adapted working method for the Umeå ESD-service was developed. In the Umeå ESD service, the patient receives a first visit in direct connection to the hospital discharge. Two team members, usually an occupational therapist and physiotherapist conduct the first visit. The patients needs and the teams' workload determines the choice of professionals. The nurse specifically visits patients who do not have an established primary care contact; the social worker visits people with special needs. The stroke physician is frequently consulted by other ESD team members, has occasionally phone contact with the stroke patients and their families and could also visit the patient in their home.

At the first visit, the patient and their family get information about the ESD service and an individual rehabilitation plan is designed. Next, daily visits are offered from someone in the ESD team. All team members work according to the patients' individual goal during the rehabilitation. An important part of the teamwork is that all professionals share their knowledge at team conferences once a week and more often if required and are able to a certain extent to work across professional borders to ensure efficient resource utilization. The ESD team has continuous contact with the home care service for supervision, instruction and evaluation of the need of assistance in activities of daily living (ADL). The home care service assists the patients and their families with tasks that they cannot handle. The ESD service ends when the patients' individual goal has been achieved. When necessary, the ESD service contacts other health care providers in the care and rehabilitation chain.

\section{Results from the Umeå ESD service}

\section{Clinical status}

During the period from 1 January 2008 to 17 May 2009, 185 patients received ESD at the stroke unit of the University Hospital of Umeå, and 153 patients fulfilled the inclusion criteria of a final diagnosis of stroke (Figure 2). Patients' baseline characteristics are summarized in Table 2. The mean length of stay was 8.6 days (range 2-57, median 7 days)at the stroke unit and 23 days (range 1-132, median 17 days)at the ESD

\begin{tabular}{|c|c|}
\hline Year & Number of patients \\
\hline 2004 & 16 \\
\hline 2005 & 74 \\
\hline 2006 & 100 \\
\hline 2007 & 133 \\
\hline 2008 & 134 \\
\hline 2009 & 169 \\
\hline
\end{tabular}

Table 1: The number of patients/yea.

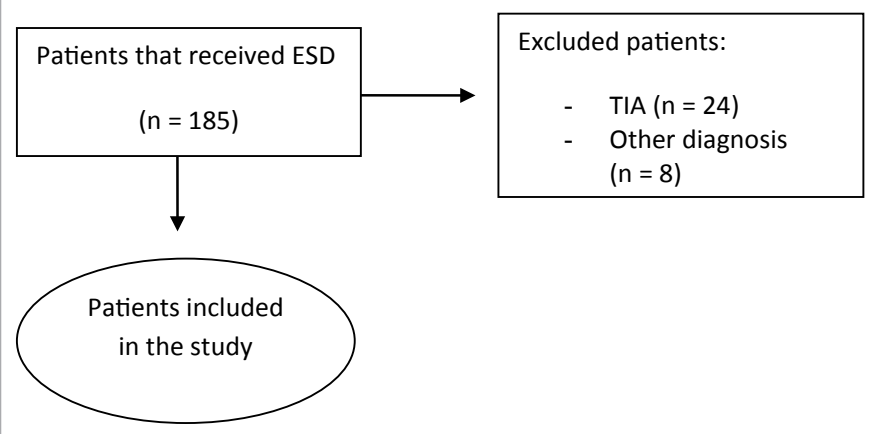

Figure 2: Flow diagrams for inclusion in the study. 
Citation: Brandal A, Wester P (2013) Stroke Unit at Home: A Prospective Observational Implementation Study for Early Supported Discharge from the Hospital. Int J Phys Med Rehabil 1: 170. doi:10.4172/2329-9096.1000170

Page 4 of 7

\begin{tabular}{|l|c|c|}
\hline Variable & \multicolumn{2}{|c|}{ ESD patients $\mathbf{n = 1 5 3}$} \\
\hline Mean age (SD) & 74 & 13.8 \\
\hline Women, $\mathrm{n}(\%)$ & 84 & 45 \\
\hline Days at the stroke unit, mean (range), SD & $8.6(2-57)$ & 5.9 \\
\hline Ischemic stroke, $\mathrm{n}(\%)$ & 142 & 93 \\
\hline Intracerebral hemorrhages, $\mathrm{n}(\%)$ & 11 & 7.2 \\
\hline Current smokern (\%) & 14 & 9.2 \\
\hline Living alone, $\mathrm{n}(\%)$ & 64 & 42 \\
\hline Modified NIH Stroke Scale (mean, range, S.D) & 2 (0-12) & 2.2 \\
\hline $\begin{array}{l}\text { ADL dependent (according to Katz ADL) prior to } \\
\text { hospital admission, } \mathrm{n} \text { (\%) }\end{array}$ & 8 & 5.2 \\
\hline Thrombolysis, $\mathrm{n}(\%)$ & 16 & 10.5 \\
\hline Previous stroken (\%) & 36 & 23,5 \\
\hline Previous TIAn (\%) & 11 & 7,2 \\
\hline Atrial fibrillationn (\%) & 34 & 22,2 \\
\hline Type 2 diabetesn (\%) & 24 & 15.7 \\
\hline Hypertension n (\%) & 88 & 57.5 \\
\hline $\begin{array}{l}\text { Modified NIH (National Institutes of Health) Stroke Scale included } \\
\text { level of consciousness, arm and leg paresis and language were }\end{array}$ & \\
\hline $\begin{array}{l}\text { evaluated at admission at the stroke unit; TIA: Transient Ischemic } \\
\text { Attack; SD: Standard Deviation }\end{array}$ & \\
\hline
\end{tabular}

Table 2: Baseline characteristics.

service. One patient experienced re-admission to the hospital during ESD service because of concealed drug abuse

\section{Functional health status}

Compared with scores assessed at enrollment, the ADL-stairs and the RMI at discharge revealed a reduced dependence during activity and increased mobility after ESD. The median ADL-stairs was $3\left(\mathrm{Q}_{1}\right.$ $\left.-\mathrm{Q}_{3} 1-5\right)$ at enrollment and $1\left(\mathrm{Q}_{1}-\mathrm{Q}_{3} 0-3\right)$ at discharge $(\mathrm{p}<0.001$, two-sided Wilcoxon Signed Ranks test).The median RMI was $11\left(\mathrm{Q}_{1}\right.$ $\left.-\mathrm{Q}_{3}, 9-13\right)$ at enrollment and $13\left(\mathrm{Q}_{1}-\mathrm{Q}_{3}, 12-15\right)$ at discharge $(\mathrm{p}$ $<0.001$, two-sided Wilcoxon Signed Ranks test). The proportion of patients who were completely or almost ADL independent (ADL stairs $0-2$ ) increased at discharge from the ESD compared with at the time of enrollment to the ESD service (Figure 3). In addition, the proportion of patients who were completely independent in their mobility in the community (RMI step 13-15) increased at discharge from the ESD compared with at the time of enrollment to the ESD service (Figure 4).

\section{Satisfaction in relation to needs}

The response rate of the Swedish National Patient Survey of Patient Satisfaction was $71 \%$ during the study period. In general, patients were satisfied with the response, information, participation in the ESD care and treatment, and availability in care and treatment (Figure 5).

\section{Costs and resources}

Table 3 shows the number of home visits and total time spent by members of each profession. The mean number of home visits by the ESD team was 11 (median 8 visits per patients). The mean time used for each patient was $18 \mathrm{~h}$ (median $14 \mathrm{~h}$ per patient). Seventy-one percent of patients received home visits from more than two team members and 4 $\%$ received home visits from the whole team.

The estimated costs of ESD at the time were 1143 Swedish Krona $(132 €)$ per visit. At the same time, costs for care in the in-hospital stroke unit totaled 6259 Swedish Krona (722 €) per day. The approximate cost of the ESD service per patient was 12.573 Swedish Krona (1429€)

\section{Accidental falls and injuries registered at the Emergency Unit}

In the Umeå University Hospital injury registry, where all patients seeking medical attention at the emergency unit because of an injury fill in a form, 25 accidents were recorded among individuals who received ESD during the period from January 2008 to May 2009. Nineteen individuals (12\%) were in the registry: five recorded accidents on two occasions. The most common injuries were fractures and wounds,

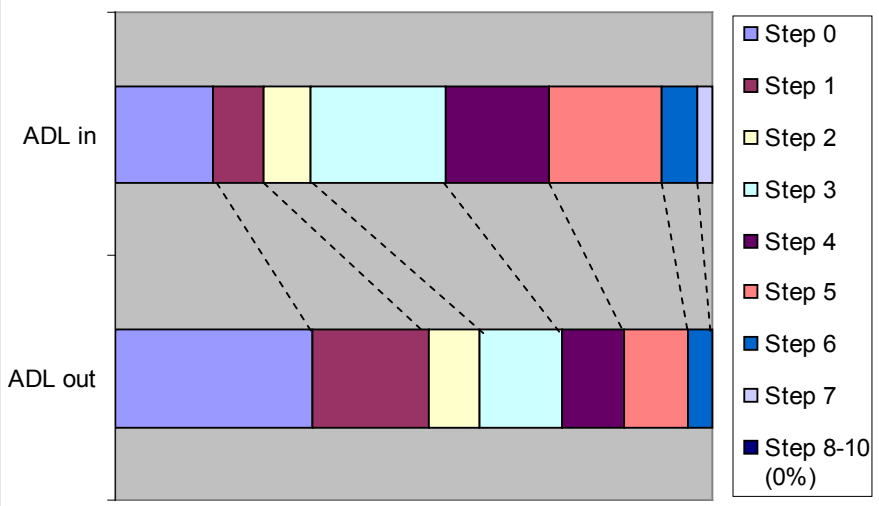

Figure 3: The percentage of subjects found at each step of the ADL-stairs (11). Step 10 means that the individual is dependent on another person for all activities: at step 0 , the person is completely independent.

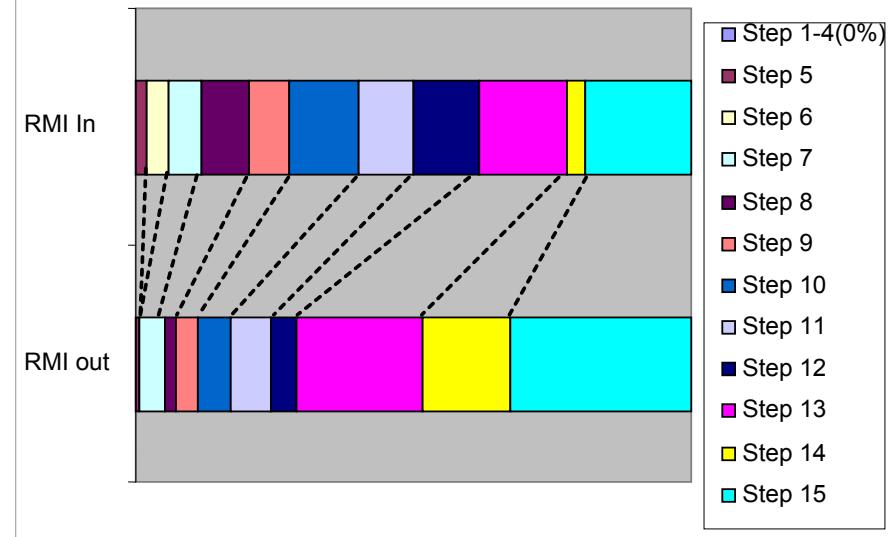

Figure 4: The percentage of subjects at each step of the RMI (12-14) where a RMI score 0 means poor mobility and 15 good mobility. RMI of 13-15 means completely independent out in the community.

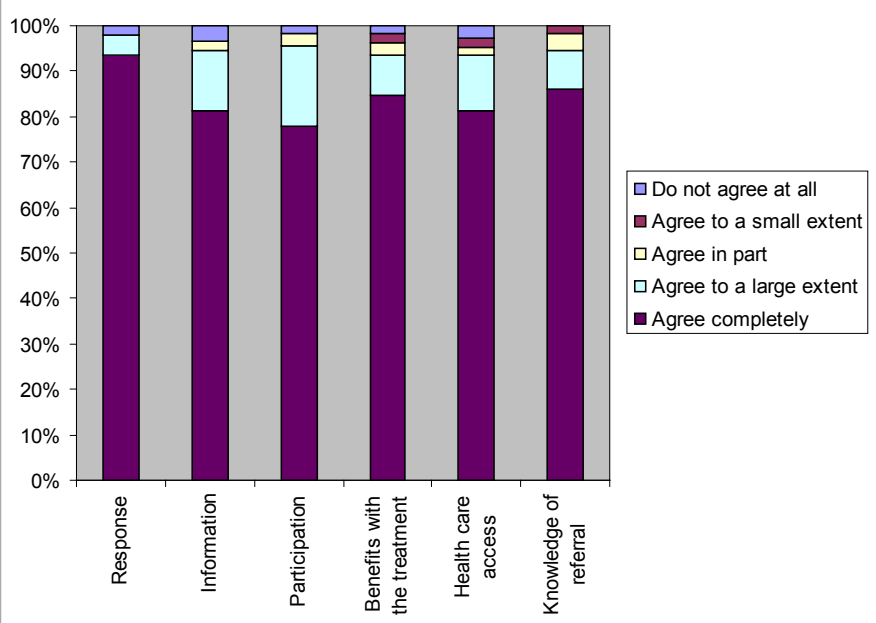

Figure 5: Patient satisfaction according to the National Patient Survey [22]. 


\begin{tabular}{|c|c|c|c|}
\hline & Patients & Number of home vistits & Total hours \\
\hline & $\mathbf{( n = 1 5 3 )}$ & Mean (Range) & Mean (Range) \\
\hline Occupational therapist & 148 & $4.5(0-36)$ & $7.5(0.5-68)$ \\
\hline Physical therapist & 148 & $4.5(0-42)$ & $7.1(0.5-55)$ \\
\hline Nurse & 110 & $1.3(0-6)$ & $2.4(0.5-12)$ \\
\hline Social worker & 40 & $0.4(0-5)$ & $1.3(0.5-13)$ \\
\hline Physician & 7 & $0.1(0-4)$ & $0.8(0.5-5)$ \\
\hline
\end{tabular}

Table 3: Numbers of home visits and number of hours, by profession.

which were classified as mild to moderate injuries according to the MAIS. One person suffered subdural hemorrhage after a fall (MAIS 4 , severe injury). Table 4 summarizes the causes, types and degrees of injury according to the MAIS.

\section{Discussion}

\section{Summary of the findings}

Both stroke unit care and early supported discharge (ESD) service are recommended for stroke patients based on randomized controlled trails summarized in systematic reviews and meta-analyses. While stroke unit care has been successfully implemented in Sweden and elsewhere, there are difficulties in transferring research results regarding the ESD stroke service to the clinic. Therefore it is considered important to adapt activities based on local conditions [8]. In addition, criticism has been raised that most of the randomized controlled trials on ESD services were published more than 10 years ago and that the efficacy and safety of ESD has not been tested in the today's stroke care with shorter hospital stay and access to hyper-acute therapies [4,24]. Our study demonstrates that it is possible to develop and implement an ESD service based on evidence-based principles, national stroke guidelines [25] and local conditions in a setting with a mean of 8,6 days, i.e., a short hospital stay at the in-hosiptal stroke unit and also with use of hyper-acute and acute interventions such as intravenous thrombolysis, mechanical thrombectomy and carotid end arterectomy within the first week in case of symptomatic carotid stenosis. The locally adapted ESD in Umeå has enabled patients to receive training in their own environment and helped them to find strategies to cope with everyday life. ESD has also offered an opportunity to support patients and their families during the initial time at home.

\section{Content, method and implementation of the Umeå ESD service}

The organization, appropriate patient volume and key elements of the Umeå stroke ESD are in agreement with the recommendations formulated by10 ESD trialists in a consensus document [8]. Thus, as recommended [8], the Umeå ESD service is hospital-based and the multi-disciplinary specialist stroke team plans and co-ordinates both the discharge from the hospital and provides the rehabilitation at home.The ESD trialists could not reach a consensus on the length of intervention by the ESD team, but agreed that the intervention should last" for as long as they need and benefit from it" [8]. In our study, there was no end date for the ESD intervention. It is interesting that the number of visits is in our study is consistent with the preliminary results from the on-going GOTVED RCT [24] that test ESD in the setting with short in-hospital stay and up-to-date acute interventions.

As summarized in the Cochrane review [4], a single ESD team should have the capacity to handles approximately 100 patients per year. This is in good agreement with the experience of the ESD service in Umeå. The majority $(71 \%)$ of patients received home visits by more than two team members. Visits by the occupational therapist and physical therapist are most common, which is expected when the focus is on rehabilitation. In our ESD team, the physician, who is a stroke specialist, is integrated in the ESD-team. The physician is frequently consulted by other ESD team members and has occasional phone contact with stroke patients and their families, which is often requested [26]. In our model of ESD, we have no specific key worker (case manager) [8] but instead, depending on the patients needs, one of the ESD team members coordinates the intervention. We have experienced strength in that the patient and their family meet different team members who provide consistent information and are able in some extent to work across professional borders. Our model is similar to the interdisciplinary team-work at the stroke unit and can be regarded as a stroke unit in the patients' home.

In our ESD-service, the stroke patients are directly transferred from the in-hospital stroke unit care to the ESD with daily visits of ESD team from the first day after hospital discharge. With this routine, the stroke patients were discharged from the hospital much earlier (mean 8.6 days) than has previously reported (mean 31 days, range 10 to 42 days) [4]. This very early supported discharge needs to be further studiedin RCT [24].

\section{Efficacy and safety}

As suggested in the ESD consensus document, the effectiveness of the Umeå ESD service in practise was measured by changes in outcome at admission and discharge [8]. The patients in this study exhibitedreduced dependence of activity and increased mobility, and were very satisfied with the ESD service. Results from the ADL-stair and the RMI show that activity levels and mobility are consistent with the recommended target group of mild to moderate stroke severity $[4,5,8,26]$.The satisfaction of ESD from patients and families has been described but more information about causes, prognosis, medication, support and practical advice is usually still requested [27]. In our ESD service, continuous information is an important part of the intervention and 80 percent of our patients reported that they were satisfied with the

\begin{tabular}{|c|c|c|}
\hline Cause of injury & Type of injury & MAIS \\
\hline Fall & Fracture & 2 \\
\hline Fall & Fracture & 2 \\
\hline Fall & Open wounds and fracture & 1 \\
\hline Fall & Fracture & 1 \\
\hline Fall & Fracture & 2 \\
\hline Fall & Subdural hemorrhage & 4 \\
\hline Bumped against something & Open wounds & 1 \\
\hline Dropped something & Contusion & 1 \\
\hline Fall & Open wounds & 1 \\
\hline Fall & Open wounds & 1 \\
\hline Fall & Open wounds and contusion & 1 \\
\hline Fall & Contusion & 1 \\
\hline Step diagonally & Distortion & 1 \\
\hline Hit from behind by a car & Distortion & 1 \\
\hline Fall & Fracture & 2 \\
\hline Fall & Lumbago & 0 \\
\hline Fall & Open wounds & 1 \\
\hline Fall & Concussion and contusion & 1 \\
\hline Fall & Contusion & 1 \\
\hline Fall & Dislocation & 2 \\
\hline Fall & Fracture and contusion & 1 \\
\hline Fall & Distortion & 1 \\
\hline Overexertion & Inflammation & 0 \\
\hline Cut on glass lamp & $\begin{array}{l}\text { Open wounds and injury to tendons } \\
\text { and muscles }\end{array}$ & 1 \\
\hline
\end{tabular}

Table 4: Causes, types and the degrees of injury. 
Citation: Brandal A, Wester P (2013) Stroke Unit at Home: A Prospective Observational Implementation Study for Early Supported Discharge from the Hospital. Int J Phys Med Rehabil 1: 170. doi:10.4172/2329-9096.1000170

Page 6 of 7

information. A weakness in our study is that there was no evaluation of the experience and needs of the carers [27].

Accidental falls was the most common injury encountered in this study. This finding is consistent with results from other studies, which found that falls are a common complication after stroke [6,28-30]. In the presentstudy, $12 \%$ suffered injuries or accidental falls within a year after onset of stroke. Other studies have reported an incidence of 43-70\% fallers at one-year follow-up [30].Our data thereby imply that there was no increased risk of accidental falls or other injuries for stroke patients receiving ESD in Umeå. One explanation for the low proportion of accidental falls can be the target group of patients with moderate stroke, but also depend on the ESD intervention. A study has previously showed increased improvement from 1 to 5 years after ESD [31]. One explanation is that ESD may start a process so that patients and family members could better cope with the life after stroke.

\section{Costs}

The total cost of care is difficult to calculate. In this study we have chosen to compare the cost of the ESD team with the daily cost of a hospital stay. Estimates of the cost of health care in the community, relatives' efforts, housing adaptations and aids, etc. are also required to obtain a more complete picture of the costs of ESD. The total health care costs for ESD service have been estimated to be equal or reduced compared with the cost for ordinary care $[4,31,32]$. Previous studies about cost without ESD service have concluded that the first period after stroke is the most expensive $[33,34]$.

\section{Conclusions}

It is possible to develop and implement ESD care for stroke patients based on evidence-based principles and local conditions. The stroke patients subjected to the Umea ESD service exhibited reduced functional dependence, increased mobility, and no apparent increased risk of accidental falls or other injuries, which was well appreciated by patients. One result of the continuous monitoring of the ESD is that the endeavor has expanded in Umeå. Two ESD teams have been operating with increased catchment $(100 \mathrm{~km})$ since May 2009 , and are able to offer ESD to patients with somewhat more severe stroke. The ESD according to the Umeå Stroke Center model, a stroke unit at home, may be an attractive alternative to conventional in-hospital stroke rehabilitation for selected patients with mild to moderate stroke.

\section{Acknowledgements}

We would like to acknowledge the whole teams at the stroke unit and the ESD service in Umeå and in particular Viveca Eklund for support in describing the methods. In addition, we thank Christer Larsson at the Memeolog department, Dr. Per-Olof Bylund at the Umeå University Hospital injury registration and associate professor Marie Ericsson for statistical support and Dr. Elias Johansson for help in gathering the Excel data-base. This study was supported by the Swedish HeartLung Foundation, the Northern Swedish Stroke Fund, the County of Västerbotten and the Medical Faculty of Umeå University.

\section{References}

1. Krishnamurthi RV, Feigin VL, Forouzanfar MH, George A Mensah MD, et al. (2013) Global and regional burden of first-ever ischaemic and haemorrhagic stroke during 1990-2010: findings from the Global Burden of Disease Study 2010. The Lancet Global Health 1: e259-e281.

2. Warlow C, Van Gijn J, Dennis M, Wardlaw J, Bamford J, et al. (2008) Stroke: Practical Management, ( $3^{\text {rd }}$ edn.), Wiley, London, UK.

3. Stroke Unit Trialists' Collaboration (2013) Organised inpatient (stroke unit) care for stroke. Cochrane Database Syst Rev 9: CD000197.

4. Fearon P, Langhorne P, Early Supported Discharge T (2012) Services for reducing duration of hospital care for acute stroke patients. Cochrane Database Syst Rev 9: CD000443.
5. Langhorne P, Holmqvist LW; Early Supported Discharge Trialists (2007) Early supported discharge after stroke. J Rehabil Med 39: 103-108.

6. Fjærtoft H, Rohweder G, Indredavik B (2011) Stroke unit care combined with early supported discharge improves 5-year outcome: a randomized controlled trial. Stroke 42: 1707-1711.

7. Thorsén AM, Holmqvist LW, de Pedro-Cuesta J, von Koch L (2005) A randomized controlled trial of early supported discharge and continued rehabilitation at home after stroke: five-year follow-up of patient outcome. Stroke 36: 297-303.

8. Fisher RJ, Gaynor C, Kerr M, Langhorne P, Anderson C, et al. (2011) A consensus on stroke: early supported discharge. Stroke 42: 1392-1397.

9. Olofsson A, Andersson SO, Carlberg B (2005) 'If only I manage to get home l'll get better'--interviews with stroke patients after emergency stay in hospital on their experiences and needs. Clin Rehabil 19: 433-440.

10. http://www.riks-stroke.org/content/english/pdf/Riks-Strokes_report_2011English.pdf

11. https://http://www.vll.se/default.aspx?id=24385\& $\mathrm{refid}=24384$

12. Alemi F, Neuhauser D, Ardito S, Headrick L, Moore S, et al. (2000) Continuous self-improvement: systems thinking in a personal context. Jt Comm J Qual Improv 26: 74-86.

13. Langley G NK, Nolan T, Norman C, Provost L (1996) The Improvement Guide: A Practical Approach to Enhancing Organizational Performance. San Francisco: Jossey-Bass Publishers.

14. Nelson EC, Batalden PB, Plume SK, Mohr JJ (1996) Improving health care, Part 2: A clinical improvement worksheet and users' manual. Jt Comm J Qual Improv 22: 531-548.

15. Nelson EC, Mohr JJ, Batalden PB, Plume SK (1996) Improving health care Part 1: The clinical value compass. Jt Comm J Qual Improv 22: 243-258.

16. van Swieten JC, Koudstaal PJ, Visser MC, Schouten HJ, van Gijn J (1988) Interobserver agreement for the assessment of handicap in stroke patients. Stroke 19: 604-607.

17. Hulter-Åsberg K (1990) ADL-trappan. Lund: Studentlitteratur.

18. KATZ S, FORD AB, MOSKOWITZ RW, JACKSON BA, JAFFE MW (1963) STUDIES OF ILLNESS IN THE AGED. THE INDEX OF ADL: A STANDARDIZED MEASURE OF BIOLOGICAL AND PSYCHOSOCIAL FUNCTION. JAMA 185: 914-919.

19. Collen FM, Wade DT, Robb GF, Bradshaw CM (1991) The Rivermead Mobility Index: a further development of the Rivermead Motor Assessment. Int Disabil Stud 13: 50-54.

20. Forlander DA, Bohannon RW (1999) Rivermead Mobility Index: a brief review of research to date. Clin Rehabil 13: 97-100.

21. Hsieh CL, Hsueh IP, Mao HF (2000) Validity and responsiveness of the rivermead mobility index in stroke patients. Scand J Rehabil Med 32: 140-142.

22. National Patient Survey.

23. Committee IIS (2005) The Abbreiated Injury Scale. Association for the Advancement of Automotive Medicine. Barrington IL.

24. Sunnerhagen KS, Danielsson A, Rafsten L, Björkdahl A, Axelsson ÅB, et al. (2013) Gothenburg very early supported discharge study (GOTVED) NCT01622205: a block randomized trial with superiority design of very early supported discharge for patients with stroke. BMC Neurol 13: 66.

25. http://www.socialstyrelsen.se/nationellariktlinjerforstrokesjukvard

26. Mas MA, Inzitari M (2012) A critical review of Early Supported Discharge for stroke patients: from evidence to implementation into practice. Int J Stroke .

27. Cobley CS, Fisher RJ, Chouliara N, Kerr M, Walker MF (2013) A qualitative study exploring patients' and carers' experiences of Early Supported Discharge services after stroke. Clin Rehabil 27: 750-757.

28. Weerdesteyn V, de Niet M, van Duijnhoven HJ, Geurts AC (2008) Falls in individuals with stroke. J Rehabil Res Dev 45: 1195-1213.

29. Indredavik B, Rohweder G, Naalsund E, Lydersen S (2008) Medical complications in a comprehensive stroke unit and an early supported discharge service. Stroke 39: 414-420.

30. Holloway RG, Tuttle D, Baird T, Skelton WK (2007) The safety of hospital stroke care. Neurology 68: 550-555. 
Citation: Brandal A, Wester P (2013) Stroke Unit at Home: A Prospective Observational Implementation Study for Early Supported Discharge from the Hospital. Int J Phys Med Rehabil 1: 170. doi:10.4172/2329-9096.1000170

31. Fjaertoft H, Indredavik B, Magnussen J, Johnsen R (2005) Early supported discharge for stroke patients improves clinical outcome. Does it also reduce use of health services and costs? One-year follow-up of a randomized controlled trial. Cerebrovasc Dis 19: 376-383.

32. Tummers JF, Schrijvers AJ, Visser-Meily JM (2012) Economic evidence on integrated care for stroke patients; a systematic review. Int J Integr Care 12: e193.
33. Jørgensen HS, Nakayama H, Raaschou HO, Olsen TS (1997) Acute stroke care and rehabilitation: an analysis of the direct cost and its clinical and socia determinants. The Copenhagen Stroke Study. Stroke 28: 1138-1141.

34. Spieler JF, Lanoë JL, Amarenco P (2004) Costs of stroke care according to handicap levels and stroke subtypes. Cerebrovasc Dis 17: 134-142.
Citation: Brandal A, Wester P (2013) Stroke Unit at Home: A Prospective Observational Implementation Study for Early Supported Discharge from the Hospital. Int J Phys Med Rehabil 1: 170. doi:10.4172/2329-9096.1000170
Submit your next manuscript and get advantages of OMICS Group submissions

Unique features:

User friendly/feasible website-translation of your paper to 50 world's leading languages

Audio Version of published paper

Digital articles to share and explore

Special features:

300 Open Access Journals

25,000 editorial team

21 days rapid review process

- Quality and quick editorial, review and publication processing

- Indexing at PubMed (partial), Scopus, EBSCO, Index Copernicus and Google Scholar etc

- Sharing Option: Social Networking Enabled

- Authors, Reviewers and Editors rewarded with online Scientific Credits

- Better discount for your subsequent articles

Submit your manuscript at: http://www.omicsonline.org/submission/ 